\title{
Níveis de manejo na cultura do milho em dois ambientes contrastantes: análise técnico-econômica
}

\author{
Maize management levels at two contrasting environmentes: \\ technical and economical analysis
}

\author{
Luis Sangoi ${ }^{1}$ Gilber Argenta ${ }^{2}$ Paulo Regis Ferreira da Silva ${ }^{3}$ \\ Tarcisio José Minetto ${ }^{4}$ Valdir Bisotto ${ }^{4}$
}

\section{RESUMO}

As práticas culturais recomendadas para cada nível de manejo na cultura do milho visam associar máxima eficiência técnica e econômica nos diferentes ambientes. No entanto, não permitem uma avaliação comparativa entre os níveis de manejo $e$ a análise de sua eficiência em ambientes contrastantes. $O$ objetivo deste trabalho foi de avaliar o retorno técnico-econômico de cinco sistemas de manejo da cultura do milho, em dois ambientes distintos. Para isto, foram conduzidos dois experimentos: um no municipio de Eldorado do Sul, localizado na Depressão Central do Rio Grande do Sul; e outro no municipio de Lages, região do Planalto Sul de Santa Catarina, no ano agrícola de 2000/2001. Em cada local, testaram-se cinco sistemas de produção $(S)$, equivalentes a diferentes níveis de manejo e expectativas de produtividade. S1, S2 e S3 representaram niveis de manejo para obtenção de baixo $\left(<3 t h a^{-1}\right)$, médio (entre $3 e$ $\left.6 t h^{-1}\right)$ e alto $\left(>6 t h^{-1}\right)$ teto de rendimento de grãos, respectivamente. $S 4$ e 55 foram sistemas propostos objetivando potencializar o rendimento de grãos. Nos dois locais, o rendimento de grãos e a margem bruta por hectare aumentaram com a elevação do nível de manejo utilizado, variando de 3,0 a 15,0 t ha ${ }^{-1}$ e $R \$ 104,86$ a $R \$ 724,77$ em Eldorado do Sul, e de 3,2 a 15,9 tha ${ }^{-1}$ e $R \$ 131,27$ a $R \$ 1.093,25$ em Lages. A cultura do milho apresentou maior retorno econômico em Lages do que em Eldorado do Sul, principalmente nos sistemas de manejo destinados a potencializar o rendimento de grãos.

Palavras-chave: Zea mays, potencial de rendimento, retorno econômico.

\section{ABSTRACT}

The cropping strategies used on different maize production systems aim to maximize technically and economically the grower's profit at each environmental condition. However, they do not allow a comparative analysis among different management strategies at an specific place neither provide the evaluation of their efficiency at different environments. This work was carried out to assess the technical and economical return of five maize management strategies at two contrasting environments. Two experiments were conducted in Southern Brazil during the growing season of 2000/2001: one in Eldorado do Sul, Rio Grande do Sul, and the other in Lages, Santa Catarina. Five production systems, corresponding to different management levels and grain yield expectations, were tested at each experimental site. $S 1, S 2$ and $S 3$ represented management levels to obtain low $\left(<3\right.$ ton $\mathrm{ha}^{-1}$ ), medium (from 3 to 6 ton $h^{-1}$ ) and high grain yield, respectively. S4 and S5 were designed to optimize grain yield. The grain yield and gross income per hectare increased with the improvement in management strategies at both study sites. In Eldorado do

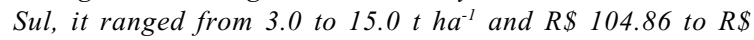
724.77. In Lages, it varied from 3.2 a $15.9 \mathrm{tha}$ hand 131.27 to 1,093.25. Maize presented higher economical return in Lages than in Eldorado do Sul, specially in the cropping systems proposed to optimize grain yield.

Key words: Zea mays, potential yield, economic return.

\footnotetext{
${ }^{1}$ Engenheiro Agrônomo, PhD., Professor Departamento de Fitotecnia/CAV-UDESC, CP 281, 88520-000, Lages, SC. Bolsista do CNPq. E-mail:a21s@cav.udesc.br. Autor para correspondência.

${ }^{2}$ Engenheiro Agrônomo, Doutor Pesquisador da FEPAGRO. Bolsita Recém-Doutor FAPERGS. E-mail: gilber.argenta@syngenta.com ${ }^{3}$ Engenheiro Agrônomo, PhD., Professor Departamento de Plantas de Lavoura/UFRGS. E-mail: paulo.silva@vortex.ufrgs.br ${ }^{4}$ FECOAGRO, Assessorias Agro/Econômica. Email:fecoagro@redeagro.com.br
} 


\section{INTRODUÇÃO}

O milho tem importância sócio-econômica significativa nos estados do Rio Grande do Sul (RS) e de Santa Catarina (SC), por se caracterizar como cultura de pequena propriedade e pela extensa área de cultivo. Segundo o Censo Agropecuário de 199596, ele está presente em 310.797 e 151.070 propriedades rurais, nos estados do RS e de SC, respectivamente (BISOTTO, 2001; ICEPA, 2000). Sua produtividade é baixa, sendo de 3,62 e de 4,40 $\mathrm{tha}^{-1}$, respectivamente, nos estados do Rio Grande do Sul e de Santa Catarina (IBGE, 2001). As baixas produtividades decorrem do uso de práticas de manejo inadequadas e do pequeno investimento em insumos feito pelos produtores (ARGENTA et al., 2001a).

As recomendações técnicas para a cultura do milho no Rio Grande do Sul diferenciam o sistema de manejo a ser adotado em função dos tetos de rendimento almejados (PROGRAMA..., 1999). Neste sentido, existem três pacotes tecnológicos propostos para baixo, médio e alto nível de manejo, objetivando expectativas de rendimento de grãos de $<3$, de 3-6 e de $>6 \mathrm{t} \mathrm{ha}^{-1}$, respectivamente. As práticas culturais recomendadas em cada nível de manejo visam maximizar técnica e economicamente a performance da cultura. No entanto, elas não permitem avaliação comparativa entre os níveis de manejo e a análise adequada do efeito do ambiente, aspecto importante visto que este possui grande influência sobre a resposta do milho aos tratos culturais utilizados e ao nível de investimento feito na lavoura.

A determinação do potencial de rendimento de grãos de milho em ambientes diferentes, sob diferentes sistemas de condução, é uma ferramenta importante para a tomada de decisões no manejo da cultura, por possibilitar a identificação dos fatores limitantes. Dimensionando-se o impacto dos fatores restritivos ao rendimento, poder-se-ão definir estratégias de como superá-los ou minimizá-los através do manejo adequado da planta e das condições ambientais. A combinação destes dois fatores permitirá maximizar a exploração dos recursos de cada ambiente de produção, buscando otimizar a produtividade das espécies de importância agrícola de uma forma sustentável (ARGENTA et al., 2001b).

A adoção de um determinado sistema de produção deve contemplar aspectos técnicos e econômicos. Assim, além da avaliação do potencial produtivo, é importante averiguar a viabilidade econômica de cada sistema nos dois ambientes. Essa, em última instância, influenciará a escolha do nível de manejo e do tipo de cultivar mais adequado para cada situação. A compatibilização das análises técnica e econômica dos sistemas de manejo propostos indicará a viabilidade de sua implementação.

O objetivo deste trabalho foi avaliar o retorno técnico e econômico de cinco sistemas de manejo da cultura do milho, em dois ambientes contrastantes.

\section{MATERIAL E MÉTODOS}

Dois experimentos foram conduzidos na estação de crescimento 2000/2001. O primeiro foi implantado em 16/10/2000, no município de Eldorado do Sul, Depressão Central do estado do Rio Grande do Sul, localizado a $30^{\circ} 05^{\prime}$ ' $52^{\prime}$ ' de latitude sul, numa altitude de \pm 46 metros acima do nível do mar. O solo da área experimental pertence à unidade de mapeamento São Jerônimo, sendo classificado como Argissolo Vermelho Distrófico Típico (EMBRAPA, 1999). O segundo experimento foi implantado em 20/10/2000, no município de Lages, Planalto Sul do estado de Santa Catarina, localizado a $27^{\circ} 52^{\prime} 30^{\prime \prime}$ de latitude sul e a 930 metros acima do nível do mar. O solo da área experimental é classificado como Nitossolo Vermelho Distrófico Típico (EMBRAPA, 1999).

Os tratamentos constaram de cinco sistemas de manejo da cultura do milho. Os sistemas S1, S2 e S3 são fundamentados nas recomendações técnicas atuais para o estado do Rio Grande do Sul para esta cultura e representam, respectivamente, baixo, médio e alto nível de manejo. Os sistemas $\mathrm{S} 4 \mathrm{e}$ S5 são propostos para potencializar o rendimento de grãos. Os cinco sistemas avaliados diferiram entre si quanto à cultivar utilizada, quantidade e época de aplicação de fertilizante, densidade de semeadura e espaçamento entre linhas.

Utilizou-se a variedade de polinização aberta CEP 304 e Amarelão do Campo Belo no sistema 1, respectivamente, em Eldorado do Sul e Lages. No sistema 2, a cultivar de milho reagente utilizada nos dois ambientes foi o híbrido duplo de ciclo precoce Agroceres 303. Nos sistemas de manejo do milho de 3 a 5, foi utilizada, nos dois ambientes, a cultivar Pioneer 32R21, híbrido simples de ciclo superprecoce. A adubação nitrogenada utilizada nos sistemas 1 a 3 foi baseada nas expectativas de rendimento de $<3,3-6$ e $>9 \mathrm{t} \mathrm{ha}^{-1}$, respectivamente, para os sistemas 1,2 e 3 . Nos sistemas 4 e 5, a adubação nitrogenada utilizada foi o dobro da utilizada no sistema 3. A adubação fosfatada e potássica utilizada nos sistemas 1 a 3 foi baseada nas recomendações técnicas para a cultura do milho no RS (PROGRAMA..., 1999). A dose utilizada de $\mathrm{P}$ e $\mathrm{K}$ foi baseada no valor de reposição 
dentro da expectativa de rendimento de $<3,3-6$ e $>6 \mathrm{t}$ $\mathrm{ha}^{-1}$, respectivamente, para os sistemas 1,2 e 3 . Nos sistemas 4 e 5, a adubação utilizada foi o dobro da utilizada no sistema 3. Nestes dois últimos sistemas, também foram aplicados os micronutrientes óxido de zinco, molibdênio e boro, nas doses de 125,5 e $1 \mathrm{~g} /$ $100 \mathrm{~kg}$ de sementes por ocasião do tratamento de sementes.

A densidade de plantas utilizada nos sistemas 1 a 3 foi baseada no nível de manejo e na expectativa de rendimento de grãos. A dos demais sistemas em função de resultados de outros experimentos (ARGENTA et al., 2001a). O espaçamento entre linhas utilizado nos sistemas 1 a 3 foi baseado nas recomendações técnicas para a cultura do milho (PROGRAMA, 1999). O dos demais sistemas em função de resultados de outros experimentos (ARGENTA et al., 2001a). As principais características de cada sistema podem ser visualizadas na tabela 1.

O delineamento experimental utilizado em cada local foi o de blocos casualizados, com quatro repetições. O experimento foi implantado em sistema de semeadura direta. Toda a adubação fosfatada e potássica foi aplicada nos sulcos de semeadura, no dia da implantação de cada ensaio, excetuando-se S4 e S5 em Eldorando do Sul. Nestes sistemas, aplicou-se metade da adubação potássica na base e metade em cobertura quando o milho apresentava seis a sete folhas expandidas. Aplicaram-se $30 \mathrm{~kg}$ de $\mathrm{N}$ na base em todos os sistemas. Nos sistemas S4 e S5 aplicaram-se 125, 5 e $1 \mathrm{~g}$ de óxido de zinco, molibdênio e boro, mais $300 \mathrm{~g}$ de i.a. do inseticida tiodicarb, para cada $100 \mathrm{~kg}$ de sementes, tratando-as no dia da semeadura com Futur. A semeadura do milho foi realizada sete dias após a dessecação da cobertura de inverno. Uma combinação de atrazina (1.400g i.a. por hectare) e metolachlor ( $2.100 \mathrm{~g}$ i.a. por hectare) foi usada para o controle de plantas daninhas.

Foi realizado desbaste, ajustando-se o número de plantas às densidades estabelecidas nos sistemas. A época de realização da cobertura nitrogenada variou de acordo com o sistema de manejo. Para os sistemas 1 e 2, efetuou-se uma aplicação em cobertura no estádio de seis a sete folhas expandidas. No Sistema 3, a cobertura nitrogenada foi parcelada em duas vezes: três a quatro e sete a oito folhas expandidas. Para S4 e S5 o parcelamento do $\mathrm{N}$ em cobertura foi feito em três épocas: três a quatro, seis a sete e 10 a 11 folhas expandidas. Efetuou-se uma aplicação de micronutrientes via foliar em S4 e S5, aspergindo-se 4 litros ha ${ }^{-1}$ do produto comercial Supa Trace, quando o milho apresentava oito folhas expandidas.

Nos sistemas 3, 4 e 5 a quantidade de água disponível no solo foi sempre mantida próxima da capacidade de campo mediante suplementação hídrica. A irrigação foi realizada quando o potencial de água no solo, mensurado por tensiômetros, foi inferior a $-0.04 \mathrm{MPa}$. O sistema de irrigação utilizado foi o de aspersão, com vazão de $12 \mathrm{~mm} /$ hora. Insetos, moléstias e plantas daninhas foram controlados sempre que necessário, com objetivo de eliminar ou atenuar estresses para a planta em S3, S4 e S5. As demais práticas de manejo adotadas seguiram as recomendações para esta cultura (INDICAÇÕES..., 2001).

A análise econômica foi baseada na metodologia utilizada pela FECOAGRO/RS (MINETTO, 2001). Utilizou-se o termo margem bruta para avaliar o retorno econômico da cultura, pois no total do dispêndio não foram consideradas as remunerações à terra, construções e às instalações.

Tabela 1 - Principais características de manejo de cinco sistemas de produção de milho em dois ambientes contrastantes, $2000 / 2001$.

\begin{tabular}{|c|c|c|c|c|c|c|}
\hline \multirow{2}{*}{$\begin{array}{l}\text { Sistemas de } \\
\text { Manejo do milho }\end{array}$} & \multicolumn{4}{|c|}{ Adubação } & \multirow{2}{*}{$\begin{array}{l}\text { Densidade de } \\
\text { plantas }\end{array}$} & \multirow{2}{*}{$\begin{array}{l}\text { Espaçamento } \\
\text { entre linhas }\end{array}$} \\
\hline & $\begin{array}{c}\text { Eldorado do Sul- } \\
\text { RS }\end{array}$ & Lages-SC & $\mathrm{P}$ & K & & \\
\hline & \multicolumn{4}{|c|}{$\mathrm{kg} \mathrm{ha}^{-1}$} & $\mathrm{pl} \mathrm{ha}^{-1}$ & $\mathrm{~cm}$ \\
\hline S1 - Baixo nível & 40 & 40 & 25 & 30 & 35.000 & 80 \\
\hline S2 - Médio nível & 80 & 70 & 40 & 60 & 50.000 & 80 \\
\hline S3 - Alto nível & 160 & 80 & 70 & 100 & 70.000 & 80 \\
\hline S4 - Potencial I & 320 & 160 & 140 & $\begin{array}{c}200+\text { micro- } \\
\text { nutrientes }\end{array}$ & 80.000 & 40 \\
\hline S5 - Potencial II & 320 & 160 & 140 & $\begin{array}{c}200+\text { micro- } \\
\text { nutrientes }\end{array}$ & 100.000 & 40 \\
\hline
\end{tabular}

Ciência Rural, v. 33, n. 6, nov-dez, 2003. 
Não foram considerados os juros sobre o desembolso. Nos custos horas/máquinas/ha estão incluídas a depreciação e a remuneração ao capital. Os valores para as irrigações $\left(\mathrm{R} \$ \mathrm{ha}^{-1}\right)$ foram embasados em dados da Emater/RS, por ha, para conjunto moto-bomba elétrica, com 200 metros de canos plásticos, aspersores a cada 12 metros e vazão de $10,3 \mathrm{~mm}_{\text {hora }}{ }^{-1}$. Os valores dos insumos tomados como referência em $1^{\circ}$ de junho de 2001 foram obtidos através de levantamentos feitos junto aos Departamentos Técnicos das cooperativas. Os preços das máquinas e dos implementos foram coletados junto aos fabricantes e pontos de venda prédeterminados no estado do Rio Grande do Sul. Os custos dos insumos utilizados para o cálculo da análise econômica podem ser visualizados na tabela 2 . Os valores para cálculo da receita bruta basearam-se no rendimento de grãos, a 13\% de umidade, com preços de junho/2001, equivalente a $\mathrm{R} \$ 7,80$ por saco de $60 \mathrm{~kg}$ de milho. Os dados de rendimento de grãos foram submetidos à análise de variância, considerando-se o ambiente como fator aleatório. Quando alcançada significância estatística, as médias foram comparadas pelo teste de Duncan, em nível de 5\% de probabilidade de erro.

\section{RESULTADOS E DISCUSSÃO}

$\mathrm{O}$ rendimento de grãos e a margem bruta por hectare aumentaram com a elevação do nível de manejo utilizado nos dois ambientes (Figura 1, Tabelas 2 e 3). Em Eldorado do Sul eles variaram de 3,0 a 15,0t e R\$ 104,86 a R\$ 724,77 por hectare. Em Lages, a variação foi de 3,2 a 15,9ton e R \$ 130,86 a R\$ 1.093,25 por hectare. Comparando-se a performance econômica dos sistemas S1 e S5, nota-se que o sistema com maior investimento em manejo incrementou a margem bruta em 591\% em Eldorado do Sul e em 733\% em Lages.

Em Eldorado do Sul, os incrementos na margem bruta foram de $109 \%$ do S1 para o S2, de $218 \%$ do S2 para o $\mathrm{S} 3$, de $-8 \%$ do S3 para o S4 e de $13 \%$ do S4 para o S5. Já em Lages, os incrementos na margem bruta foram de $123 \%$ do $\mathrm{S} 1$ para o S2, de

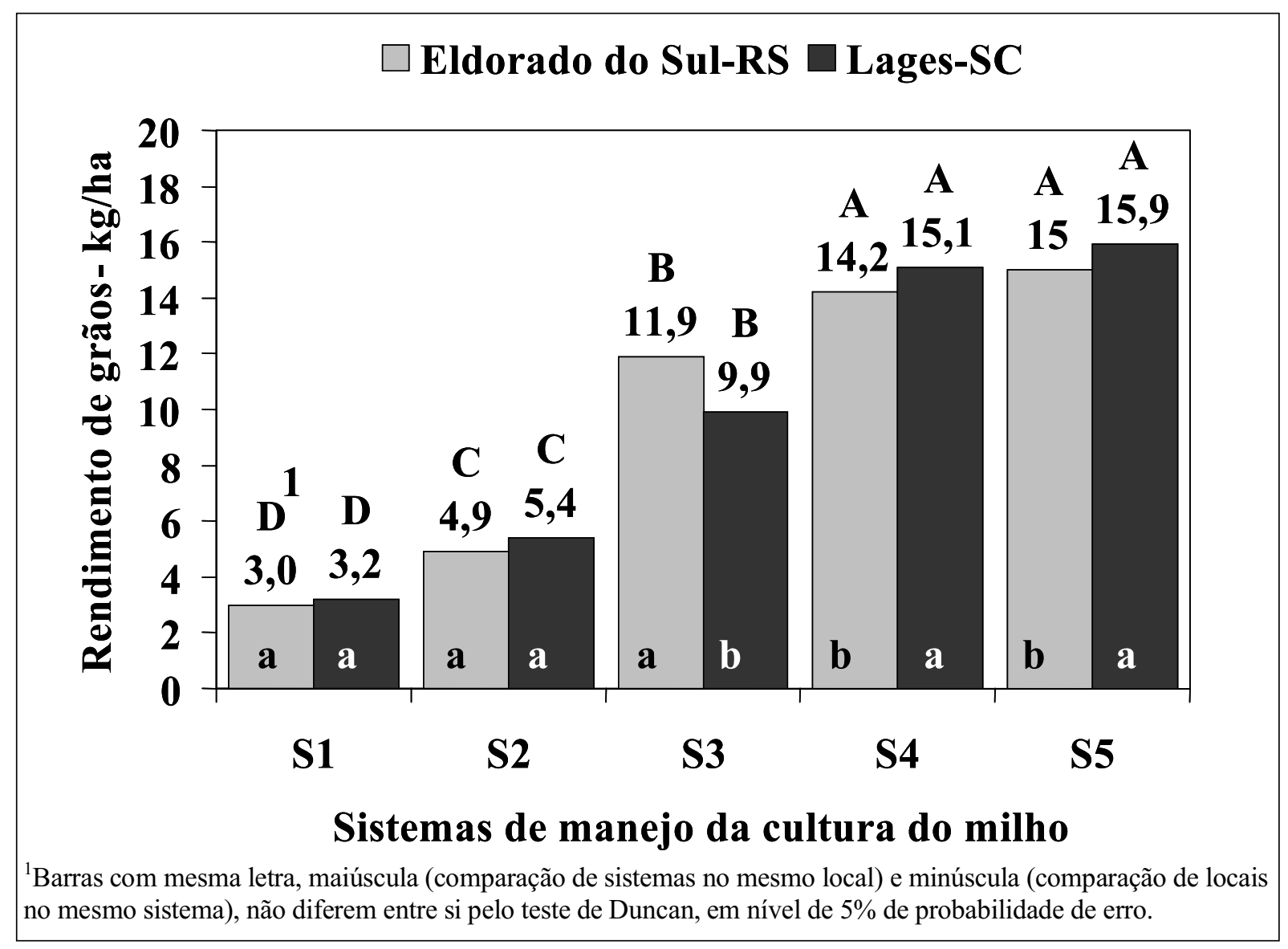

Figura 1 - Rendimento de grãos de milho em função de cinco sistemas de manejo de milho em dois locais contrastantes. 2000/2001. S1= baixo nível de manejo; S2= médio nível de manejo; S3= alto nível de manejo; S4 e S5= potenciais de rendimento de grãos. 
Tabela 2 - Custos, receitas e margens brutas em função dos sistemas de baixo (S1), médio (S2) e alto (S3) manejo do milho, em dois locais, $2000 / 2001$.

\begin{tabular}{|c|c|c|c|}
\hline \multicolumn{4}{|c|}{ LOCAL } \\
\hline \multicolumn{2}{|c|}{ Eldorado do Sul-RS } & \multicolumn{2}{|c|}{ Lages-SC } \\
\hline Sistema de manejo 1 & $\mathbf{R} \$ \mathrm{ha}^{-1}$ & Sistema de manejo 1 & R\$ ha ${ }^{-1}$ \\
\hline Cultivar CEP $304\left(15 \mathrm{~kg} \mathrm{ha}^{-1}\right)$ & 24,00 & Cultivar Amarelão (15 $\left.\mathrm{kg} \mathrm{ha}^{-1}\right)$ & 24,00 \\
\hline Trat. Semente (Semevin $0,3 \mathrm{~L} \mathrm{ha}^{-1}$ ) & 14,40 & Trat. Semente (Semevin $0,3 \mathrm{~L} \mathrm{ha}^{-1}$ ) & 14,40 \\
\hline Adubação & & Adubação & \\
\hline Uréia $\left(89 \mathrm{~kg} \mathrm{ha}^{-1}\right)$ & 36,49 & Uréia (89 kg ha $\left.{ }^{-1}\right)$ & 36,49 \\
\hline SFT $\left(60 \mathrm{~kg} \mathrm{ha}^{-1}\right)$ & 27,00 & SFT (60 kg ha $\left.{ }^{-1}\right)$ & 27,00 \\
\hline $\mathrm{KCl}\left(50 \mathrm{~kg} \mathrm{ha}^{-1}\right)$ & 21,50 & $\mathrm{KCl}\left(50 \mathrm{~kg} \mathrm{ha}^{-1}\right)$ & 21,50 \\
\hline Herbicida (Controler $6 \mathrm{~L} \mathrm{ha}^{-1}$ ) & 45,00 & Herbicida (Controler $6 \mathrm{~L} \mathrm{ha}^{-1}$ ) & 45,00 \\
\hline Máquinas & & Máquinas & \\
\hline $1 *$ Semeadura & 26,60 & $1 *$ Semeadura & 26,60 \\
\hline 1* Aplicação de herbicida & 10,80 & 1* Aplicação de herbicida & 10,80 \\
\hline 1* Aplicação de nitrogênio & 13,10 & 1* Aplicação de nitrogênio & 13,10 \\
\hline $1 *$ Colheita & 66,25 & $1 *$ Colheita & 66,25 \\
\hline TOTAL DO DISPÊNDIO & 285,14 & TOTAL DO DISPÊNDIO & 285,14 \\
\hline RECEITA BRUTA $\left(3,0 \mathrm{t} \mathrm{ha}^{-1}\right)$ & 390,00 & RECEITA BRUTA $\left(3,2 \mathrm{t} \mathrm{ha}^{-1}\right)$ & 416,00 \\
\hline MARGEM BRUTA & 104,86 & MARGEM BRUTA & 130,86 \\
\hline Sistema de manejo 2 & $\mathbf{R} \$ \mathrm{ha}^{-1}$ & Sistema de manejo 2 & $\mathbf{R} \$ \mathrm{ha}^{-1}$ \\
\hline Cultivar AG $303\left(20 \mathrm{~kg} \mathrm{ha}^{-1}\right)$ & 80,00 & Cultivar AG $303\left(20 \mathrm{~kg} \mathrm{ha}^{-1}\right)$ & 80,00 \\
\hline Trat. semente (Semevin $0,4 \mathrm{~L} \mathrm{ha}^{-1}$ ) & 19,20 & Trat. Semente (Semevin $0,4 \mathrm{~L} \mathrm{ha}^{-1}$ ) & 19,20 \\
\hline Adubação & & Adubação & \\
\hline Uréia (178 kg ha $\left.{ }^{-1}\right)$ & 72,98 & Uréia (156 kg ha-1) & 63,96 \\
\hline SFT $\left(95 \mathrm{~kg} \mathrm{ha}^{-1}\right)$ & 40,85 & SFT $\left(95 \mathrm{~kg} \mathrm{ha}^{-1}\right)$ & 40,85 \\
\hline $\mathrm{KCl}\left(100 \mathrm{~kg} \mathrm{ha}^{-1}\right)$ & 43,00 & $\mathrm{KCl}\left(100 \mathrm{~kg} \mathrm{ha}^{-1}\right)$ & 43,00 \\
\hline Herbicida (Controler $6 \mathrm{~L} \mathrm{ha}^{-1}$ ) & 45,00 & Herbicida (Controler $6 \mathrm{~L} \mathrm{ha}^{-1}$ ) & 45,00 \\
\hline Máquinas & & Máquinas & \\
\hline $1 *$ Semeadura & 26,60 & $1 *$ Semeadura & 26,60 \\
\hline $1^{*}$ Aplicação de herbicida & 10,80 & $1^{*}$ Aplicação de herbicida & 10,80 \\
\hline 1* Aplicação de nitrogênio & 13,10 & $1^{*}$ Aplicação de nitrogênio & 13,10 \\
\hline $1 *$ Colheita & 66,25 & $1 *$ Colheita & 66,25 \\
\hline TOTAL DO DISPÊNDIO & 417,78 & TOTAL DO DISPÊNDIO & 408,76 \\
\hline RECEITA BRUTA $\left(4,9 \mathrm{t} \mathrm{ha}^{-1}\right)$ & 637,00 & RECEITA BRUTA $\left(5,4 \mathrm{t} \mathrm{ha}^{-1}\right)$ & 702,00 \\
\hline MARGEM BRUTA & 219,22 & MARGEM BRUTA & 293,24 \\
\hline Sistema de manejo 3 & R\$ ha ${ }^{-1}$ & Sistema de manejo 3 & $\mathbf{R} \$ \mathbf{h a}^{-1}$ \\
\hline Cultivar P32R21 $\left(20 \mathrm{~kg} \mathrm{ha}^{-1}\right)$ & 100,00 & Cultivar P32R21 $\left(20 \mathrm{~kg} \mathrm{ha}^{-1}\right)$ & 100,00 \\
\hline Trat. semente (Semevin $0,4 \mathrm{~L} \mathrm{ha}^{-1}$ ) & 19,20 & Trat. Semente (Semevin $0,4 \mathrm{~L} \mathrm{ha}^{-1}$ ) & 19,20 \\
\hline Adubação & & Adubação & \\
\hline Uréia $\left(356 \mathrm{~kg} \mathrm{ha}^{-1}\right)$ & 145,96 & Uréia $\left(178 \mathrm{~kg} \mathrm{ha}^{-1}\right)$ & 72,98 \\
\hline SFT $\left(167 \mathrm{~kg} \mathrm{ha}^{-1}\right)$ & 75,15 & SFT (167 kg ha $\left.{ }^{-1}\right)$ & 75,15 \\
\hline $\mathrm{KCl}\left(167 \mathrm{~kg} \mathrm{ha}^{-1}\right)$ & 71,81 & $\mathrm{KCl}\left(167 \mathrm{~kg} \mathrm{ha}^{-1}\right)$ & 71,81 \\
\hline Herbicida (Controler $6 \mathrm{~L} \mathrm{ha}^{-1}$ ) & 45,00 & Herbicida (Controler $6 \mathrm{~L} \mathrm{ha}^{-1}$ ) & 45,00 \\
\hline Inseticida & & Inseticida & \\
\hline $2 *$ Karate $\left(0,15 \mathrm{~L} \mathrm{ha}^{-1}\right)$ & 13,50 & $1 * \operatorname{Match}\left(0,25 \mathrm{~L} \mathrm{ha}^{-1}\right)$ & 7,81 \\
\hline $1 * \operatorname{Lorsban}\left(0,4 \mathrm{~L} \mathrm{ha}^{-1}\right)$ & 6,72 & & \\
\hline \multicolumn{4}{|l|}{ Fungicida } \\
\hline $2 *$ Derosal $\left(0,5 \mathrm{~L} \mathrm{ha}^{-1}\right)$ & 34,00 & & \\
\hline $2 *$ Manzate $\left(2 \mathrm{~kg} \mathrm{ha}^{-1}\right)$ & 31,20 & & \\
\hline Irrigação & & Irrigação & \\
\hline $5^{*}$ Irrigações (total 14 horas) & 145,00 & 4* Irrigações (total 8 horas) & 105,00 \\
\hline
\end{tabular}

Ciência Rural, v. 33, n. 6, nov-dez, 2003. 
Tabela 2 - Continuação

\begin{tabular}{|c|c|c|c|}
\hline Máquinas & & Máquinas & \\
\hline $1 *$ Semeadura & 26,60 & $1 *$ Semeadura & 26,60 \\
\hline 1* Aplicação de herbicida & 10,80 & 1* Aplicação de herbicida & 10,80 \\
\hline 3* Aplicações de fung./inseticidas & 32,40 & 1* Aplicação de inseticida & 10.80 \\
\hline 2* Aplicação de nitrogênio/potássio & 26,20 & 2* Aplicações de nitrogênio & 26,20 \\
\hline $1 *$ Colheita & 66,25 & $1 *$ Colheita & 66,25 \\
\hline TOTAL DO DISPÊNDIO & 849,79 & TOTAL DO DISPÊNDIO & 637,60 \\
\hline RECEITA BRUTA $\left(11,9 \mathrm{t} \mathrm{ha}^{-1}\right)$ & $1.547,00$ & RECEITA BRUTA $\left(9,9 \mathrm{t} \mathrm{ha}^{-1}\right)$ & $1.287,00$ \\
\hline MARGEM BRUTA & 697,21 & MARGEM BRUTA & 649,40 \\
\hline
\end{tabular}

Refere-se ao número de operações efetuadas.

$121 \%$ do S 2 para o S3, de $58 \%$ do S 3 para o S 4 e de $7 \%$ do S4 para o S5. Estes resultados evidenciam que o maior impacto, em termos de aumento na margem bruta, foi obtido na mudança do sistema S2 para o S3, em Eldorado do Sul, e do S1 para o S2, em Lages. Esta resposta diferencial entre locais pode ser atribuída, principalmente, ao fato do rendimento de grãos de milho no S3 em Lages ter sido abaixo do esperado, por ter ocorrido deficiência de N. A quantidade de nitrogênio utilizada foi insuficiente para sustentar tetos de produtividade superiores a $10 \mathrm{t} \mathrm{ha}^{-1}$ (SANGOI et al., 2001), mesmo num solo com alto teor de matéria orgânica.

Fazendo-se um paralelo dos resultados obtidos com os ocorridos à nível das propriedades rurais, verifica-se que o rendimento de grãos de milho registrado pela maioria dos produtores rurais nos estados do RS e de $\mathrm{SC}$ nos últimos anos é semelhante ao verificado no sistema S1 e inferior ao obtido em S2. Isto evidencia que grande parte dos produtores rurais investe muito pouco em tecnologia, utilizando baixo nível de manejo. Os resultados deste trabalho evidenciam que a utilização de práticas de manejo pouco onerosas, como as empregadas em S2, praticamente dobrou o rendimento de grãos de milho e a margem bruta por hectare (Tabela 2). Extrapolando-se os resultados obtidos nos dois ambientes para os estados do Rio Grande do Sul e Santa Catarina, pode-se hipotetizar que uma pequena melhoria no manejo da cultura do milho ocasionaria incrementos significativos na produção de grãos deste cereal no sul do Brasil.

$\mathrm{O}$ incremento na produtividade do milho, decorrente da melhoria nas práticas de manejo, é fundamental para a manutenção do pequeno produtor na atividade. A margem bruta computada por hectare em S1 foi de apenas R $\$ 118,00$, na média dos dois locais. Considerando-se que muitos produtores do sul do Brasil utilizam sistemas de produção semelhantes a este e que a área média de cultivo é de aproximadamente 5 ha, têm- se uma margem bruta por propriedade por ano com o milho de $\mathrm{R} \$ 590,00$, eqüivalendo a uma margem bruta de $\mathrm{R} \$ 49,00 \mathrm{mês}^{-1}$. Desta forma, se não houver agregação de valores na propriedade, a receita gerada pelo milho é insuficiente para manter o pequeno produtor na atividade.

A análise econômica comparativa entre locais, para cada sistema de manejo, mostra que no S1 o total de dispêndio foi similar entre os ambientes (Tabela 2). No entanto, a margem bruta foi $24,8 \%$ maior em Lages do que em Eldorado do Sul, devido ao maior rendimento de grãos $\left(200 \mathrm{~kg} \mathrm{ha}^{-1}\right)$. No S2, novamente a margem bruta foi maior $(33,8 \%)$ em Lages em relação a Eldorado do Sul. Neste caso, além do rendimento de grãos ter sido inferior $\left(500 \mathrm{~kg} \mathrm{ha}^{-1}\right)$ em Eldorado do Sul-RS, houve maior gasto, principalmente, com adubação nitrogenada neste local. O S3 apresentou margem bruta 7,4\% superior em Eldorado do Sul em relação a Lages. Este fato pode ser atribuído à limitação imposta ao rendimento de grãos de milho em Lages pela insuficiente quantidade de $\mathrm{N}$ utilizada neste sistema $\left(80 \mathrm{~kg} \mathrm{ha}^{-1}\right)$ reportada por ARGENTA et al. (2001b), uma vez que houve maiores dispêndios com adubação nitrogenada, inseticida, fungicida, irrigações e com utilização de máquinas em Eldorado do Sul. Com relação aos sistemas potenciais de manejo (S4 e S5), nota-se que a margem bruta em Lages superou em mais de $50 \%$ àquela obtida em Eldorado do Sul (Tabela 3). Portanto, as maiores diferenças entre locais na margem bruta foram obtidas nos sistemas que buscaram otimizar a performance da cultura.

Estes resultados evidenciam que, com exceção de S3, a margem bruta foi sempre maior em Lages do que em Eldorado do Sul. Os principais fatores responsáveis por esta resposta foram: a) maior altitude de Lages em relação à Eldorado do Sul, possibilitando a obtenção de maior rendimento de grãos (Figura 1) devido, principalmente, a menor respiração à noite (ANDRADE et al., 1993); b) menor incidência de pragas e moléstias, que é superior em regiões com temperaturas 
Tabela 3 - Custos, receitas e margens brutas em função dos sistemas potenciais de manejo (S4 e S5) do milho, em dois locais, $2000 / 2001$.

\begin{tabular}{|c|c|c|c|}
\hline \multicolumn{4}{|c|}{ LOCAL } \\
\hline \multicolumn{2}{|c|}{ Eldorado do Sul-RS } & \multicolumn{2}{|c|}{ Lages-SC } \\
\hline Sistema de manejo 4 & RS ha ${ }^{-1}$ & Sistema de manejo 4 & R\$ ha ${ }^{-1}$ \\
\hline Cultivar P32R21 (23 kg ha $\left.{ }^{-1}\right)$ & 115,00 & Cultivar P32R21 (23 kg ha-1) & 115,00 \\
\hline Trat. semente (Futur $0,46 \mathrm{~L} \mathrm{ha}^{-1}$ ) & 20,70 & Trat. semente (Futur $0,46 \mathrm{~L} \mathrm{ha}^{-1}$ ) & 20,70 \\
\hline Adubação & & Adubação & \\
\hline Uréia (712 kg ha $\left.{ }^{-1}\right)$ & 291,92 & Uréia (356 kg ha $\left.{ }^{-1}\right)$ & 145,96 \\
\hline SFT (334 kg ha $\left.{ }^{-1}\right)$ & 150,30 & SFT (334 kg ha $\left.{ }^{-1}\right)$ & 150,30 \\
\hline $\mathrm{KCl}\left(334 \mathrm{~kg} \mathrm{ha}^{-1}\right)$ & 143,62 & $\mathrm{KCl}\left(334 \mathrm{~kg} \mathrm{ha}^{-1}\right)$ & 143,62 \\
\hline Herbicida (Controler $6 \mathrm{~L} \mathrm{ha}^{-1}$ ) & 45,00 & Herbicida (Controler $6 \mathrm{~L} \mathrm{ha}^{-1}$ ) & 45,00 \\
\hline Inseticida & & Inseticida & \\
\hline $2 *$ Karate $\left(0,15 \mathrm{~L} \mathrm{ha}^{-1}\right)$ & 13,50 & $2 * \operatorname{Match}\left(0,25 \mathrm{~L} \mathrm{ha}^{-1}\right)$ & 15,62 \\
\hline $2 * \operatorname{Lorsban}\left(0,4 \mathrm{~L} \mathrm{ha}^{-1}\right)$ & 13,44 & & \\
\hline Fungicida & & Fungicida & \\
\hline $2 *$ Derosal $\left(0,5 \mathrm{~L} \mathrm{ha}^{-1}\right)$ & 34,00 & $1 *$ Derosal $\left(0,5 \mathrm{~L} \mathrm{ha}^{-1}\right)$ & 17,00 \\
\hline $2 *$ Manzate $\left(2 \mathrm{~kg} \mathrm{ha}^{-1}\right)$ & 31,20 & $1 *$ Manzate $\left(2 \mathrm{~kg} \mathrm{ha}^{-1}\right)$ & 15,60 \\
\hline Irrigação & & Irrigação & \\
\hline $5 *$ Irrigações (total 14 horas) & 145,00 & 4* Irrigações (total 8 horas) & 105,00 \\
\hline Máquinas & & Máquinas & \\
\hline $1 *$ Semeadura & 26,60 & $1 *$ Semeadura & 26,60 \\
\hline 1* Aplicação de herbicida & 10,80 & 1* Aplicação de herbicida & 10,80 \\
\hline 4* Aplicações de fung./inseticidas & 43,20 & $2 *$ Aplicações de fung./inseticidas & 21,60 \\
\hline 3* Aplicação de nitrogênio/potássio & 39,30 & 3* Aplicações de nitrogênio & 39,30 \\
\hline $1 *$ Colheita & 66,25 & $1 *$ Colheita & 66,25 \\
\hline TOTAL DO DISPÊNDIO & $1.189,83$ & TOTAL DO DISPÊNDIO & 938,35 \\
\hline RECEITA BRUTA $\left(14,1 \mathrm{t} \mathrm{ha}^{-1}\right)$ & $1.833,00$ & RECEITA BRUTA $\left(15,1 \mathrm{t} \mathrm{ha}^{-1}\right)$ & $1.963,00$ \\
\hline MARGEM BRUTA & 643,17 & MARGEM BRUTA & $1.024,65$ \\
\hline Sistema de manejo 5 & R\$ ha ${ }^{-1}$ & Sistema de manejo 5 & $\mathbf{R} \$ \mathbf{h a}^{-1}$ \\
\hline Cultivar P32R21 (29 $\left.\mathrm{kg} \mathrm{ha}^{-1}\right)$ & 145,00 & Cultivar P32R21 (29 $\left.\mathrm{kg} \mathrm{ha}^{-1}\right)$ & 145,00 \\
\hline Trat. semente (Futur $0,58 \mathrm{~L} \mathrm{ha}^{-1}$ ) & 26,10 & Trat. semente (Futur $0,58 \mathrm{~L} \mathrm{ha}^{-1}$ ) & 26,10 \\
\hline Adubação & & Adubação & \\
\hline Uréia $\left(712 \mathrm{~kg} \mathrm{ha}^{-1}\right)$ & 291,92 & Uréia $\left(356 \mathrm{~kg} \mathrm{ha}^{-1}\right)$ & 145,96 \\
\hline SFT (334 kg ha $\left.{ }^{-1}\right)$ & 150,30 & SFT $\left(334 \mathrm{~kg} \mathrm{ha}^{-1}\right)$ & 150,30 \\
\hline $\mathrm{KCl}\left(334 \mathrm{~kg} \mathrm{ha}^{-1}\right)$ & 143,62 & $\mathrm{KCl}\left(334 \mathrm{~kg} \mathrm{ha}^{-1}\right)$ & 143,62 \\
\hline Herbicida (Controler $6 \mathrm{~L} \mathrm{ha}^{-1}$ ) & 45,00 & Herbicida (Controler $6 \mathrm{~L} \mathrm{ha}^{-1}$ ) & 45,00 \\
\hline Inseticida & & Inseticida & \\
\hline $2 *$ Karate $\left(0,15 \mathrm{~L} \mathrm{ha}^{-1}\right)$ & 13,50 & $2 * \operatorname{Match}\left(0,25 \mathrm{~L} \mathrm{ha}^{-1}\right)$ & 15,62 \\
\hline $2 *$ Lorsban $\left(0,4 \mathrm{~L}\right.$ ha $\left.^{-1}\right)$ & 13,44 & & \\
\hline Fungicida & & Fungicida & \\
\hline $2 *$ Derosal $\left(0,5 \mathrm{~L} \mathrm{ha}^{-1}\right)$ & 34,00 & $1 *$ Derosal $\left(0,5 \mathrm{~L} \mathrm{ha}^{-1}\right)$ & 17,00 \\
\hline $2 *$ Manzate $\left(2 \mathrm{~kg} \mathrm{ha}^{-1}\right)$ & 31,20 & $1 *$ Manzate $\left(2 \mathrm{~kg} \mathrm{ha}^{-1}\right)$ & 15,60 \\
\hline Irrigação & & Irrigação & \\
\hline 5* Irrigações (total 14 horas) & 145,00 & 4* Irrigações (total 8 horas) & 105,00 \\
\hline Máquinas & & Máquinas & \\
\hline $1 *$ Semeadura & 26,60 & $1 *$ Semeadura & 26,60 \\
\hline 1* Aplicação de herbicida & 10,80 & 1* Aplicação de herbicida & 10,80 \\
\hline 4* Aplicações de fung./inseticidas & 43,20 & 2* Aplicações de fung./inseticidas & 21,60 \\
\hline 3* Aplicação de nitrogênio/potássio & 39,30 & 3* Aplicações de nitrogênio & 39,30 \\
\hline $1 *$ Colheita & 66,25 & $1 *$ Colheita & 66,25 \\
\hline TOTAL DO DISPÊNDIO & $1.225,23$ & TOTAL DO DISPÊNDIO & 973,75 \\
\hline RECEITA BRUTA $\left(15,0 \mathrm{t} \mathrm{ha}^{-1}\right)$ & $1.950,00$ & RECEITA BRUTA $\left(15,9 \mathrm{t} \mathrm{ha}^{-1}\right)$ & $2.067,00$ \\
\hline MARGEM BRUTA & 724,77 & MARGEM BRUTA & $1.093,25$ \\
\hline
\end{tabular}

*Refere-se ao número de operações efetuadas. 
altas, com maior insolação e com maior variação na disponibilidade de água (GASSEN, 1996, PEGORARO et al., 2001); c) maior fertilidade do solo, que permite menor investimento em adubação, principalmente a nitrogenada, devido ao maior suprimento de $\mathrm{N}$ para o milho pelo solo de Lages em relação ao de Eldorado do Sul, uma vez que o teor de matéria orgânica de seu solo é maior (AMADO \& MIELNICZUK, 2000, ARGENTA et al., 2001c); e d) menor investimento em irrigação em Lages em relação a Eldorado do Sul, pois a evapotranspiração do milho é menor em regiões de maior altitude. Nestes ambientes, a demanda evaporativa da atmosfera é menor devido a menor temperatura atmosférica e menor quantidade de radiação solar (SANGOI, 1993; MATZENAUER et al., 2000).

Os acréscimos nos custos de produção, o capital investido e os riscos do investimento são pontos que devem ser levados em consideração para recomendar mudanças no manejo da cultura do milho. A análise da variação conjunta de receita bruta e dispêndio ocasionada pela mudança de sistemas de produção mostrou um comportamento distinto entre ambientes (Tabela 4). Em Eldorado do Sul houve ganhos marcantes com a elevação do investimento em manejo até S3. Já em Lages ocorreram incrementos substanciais na margem bruta sempre que o nível de manejo foi melhorado. Estes resultados evidenciam que a utilização de estratégias de manejo destinadas a potencializar o rendimento de grãos do milho em Eldorado do Sul não foram economicamente eficientes, pois os incrementos de produtividade ocorreram às custas de muito investimento. Por outro lado, em Lages houve benefícios econômicos na adoção de práticas culturais que otimizassem a exploração do ambiente.

Assim, em Eldorado do Sul o produtor não têm, a curto prazo, vantagens econômicas em relação a margem bruta para tentar maximizar o rendimento de grãos através do manejo. Contudo, tais benefícios poderão se manifestar a médio e longo prazo, visto que sistemas com maior nível de manejo melhoram as características físico, química e biológicas do solo, devido ao fato produzirem mais massa seca, decorrente do maior investimento em adubação (AMADO et al., 2001). A região de Lages apresenta características edafo-climáticas que favorecem um maior investimento na adoção de estratégias que permitam ao milho expressar o seu potencial produtivo

Independentemente do ambiente onde seja cultivado, um ponto fundamental para a melhoria do manejo na cultura do milho é adoção de uma política agrícola coerente, que remunere adequadamente o produto colhido. A manutenção do preço do saco de $60 \mathrm{~kg}$ de milho na faixa de $\mathrm{R} \$ 7,00$ a $\mathrm{R} \$ 8,00$ dificilmente incentivará os produtores a investirem em inovações tecnológicas. Preços neste patamar fazem com que, dependendo da região, ou mesmo da época de semeadura, o retorno econômico gerado por incrementos na qualidade do sistema produtivo sejam inferiores ao capital investido na lavoura.

\section{CONCLUSÕES}

O maior investimento em práticas de manejo incrementa o rendimento de grãos e a margem bruta da cultura do milho, independente do local.

Tabela 4 - Alteração na margem bruta em função de mudanças no sistema de manejo utilizado, em dois locais. 2000/2001.

\begin{tabular}{|c|c|c|c|c|}
\hline \multirow{2}{*}{$\begin{array}{l}\text { Sistemas de manejo do } \\
\text { milho }\end{array}$} & \multicolumn{4}{|c|}{ Sistema de manejo do milho } \\
\hline & Médio (S2) & Alto (S3) & Potencial I (S4) & Potencial II (S5) \\
\hline & \multicolumn{4}{|c|}{ Eldorado do Sul-RS - Margem bruta real $\left(\mathrm{R} \$ \mathrm{ha}^{-1}\right)^{1}$} \\
\hline Baixo (S1) & 114,36 & 592,35 & 538,31 & 619,91 \\
\hline Médio (S2) & -- & 477,99 & 423,95 & 505,55 \\
\hline Alto (S3) & -- & -- & $-54,04$ & 27,56 \\
\hline \multirow[t]{2}{*}{ Potencial I (S4) } & -- & -- & -- & 81,60 \\
\hline & \multicolumn{4}{|c|}{ Lages-SC - Margem bruta real $\left(\mathrm{R} \$ h^{-1}\right)^{1}$} \\
\hline Baixo (S1) & 162,38 & 518,54 & 893,79 & 962,39 \\
\hline Médio (S2) & -- & 356,16 & 731,41 & 800,01 \\
\hline Alto (S3) & -- & -- & 375,25 & 443,85 \\
\hline Potencial I (S4) & -- & -- & -- & 68,60 \\
\hline
\end{tabular}

${ }^{1}$ Alteração na margem bruta de S1 para S2 = (receita bruta S2 - receita bruta S1) - (dispêndio S2 - dispêndio S1); S1 para S3= (receita bruta $\mathrm{S} 3$ - receita bruta $\mathrm{S} 1)$ - (dispêndio S3 - dispêndio S1);...Sn1 para Sn2 = (receita bruta Sn2 - receita bruta Sn1) - (dispêndio Sn2 - dispêndio $\mathrm{Sn} 1)$. 
Em Lages é possível associar máxima eficiência técnica com máxima eficiência econômica através do manejo.

A cultura do milho apresenta maior retorno econômico em Lages do que em Eldorado do Sul, principalmente nos sistemas de manejo estabelecidos para otimizar a performance da lavoura.

\section{REFERÊNCIAS BIBLIOGRÁFICAS}

AMADO, T.J.C. et al. Potencial de culturas de cobertura em acumular carbono e nitrogênio no solo no plantio direto e a melhoria da qualidade ambiental. Revista Brasileira de Ciência do Solo, Campinas, v.25, n.1, p.189-197, 2001

AMADO, T.J.C.; MIELNICZUK, J. Estimativa da adubação nitrogenada para o milho em sistemas de manejo e culturas de cobertura do solo. Revista Brasileira de Ciência do Solo, Campinas, v.24, n.3, p.553-560, 2000

ANDRADE, F.H.; UHART, S.A.; CIRILO, A. Temperature affects radiation use efficiency in maize. Field Crops Research, Amsterdan, v.32, p.17-25, 1993

ARGENTA, G.; SILVA, P.R.F. da; SANGOI, L. Arranjo de plantas em milho: análise do estado-da-arte. Ciência Rural, Santa Maria, v.31, n.5, p.1075-1084, 2001a.

ARGENTA, G. et al. Potencial de rendimento de grãos de milho em dois ambientes contrastantes. Scientia Agraria, Piracicaba, 2001b. no prelo.

ARGENTA, G. et al. Parâmetros de planta como indicadores do nível de nitrogênio na cultura do milho. Pesquisa Agropecuária Brasileira, Brasília, v.37, n.4, p.519-527, $2001 \mathrm{c}$.

BARNI, N.A. et al. Rendimento máximo do girassol com base na radiação solar e temperatura: II. Produção de fitomassa e rendimento de grãos. Pesquisa Agropecuária Gaúcha, Porto Alegre, v.1, p.201-216, 1995.

BISOTTO, V. Algumas considerações sobre a cultura do milho. In: FEPAGRO; EMBRAPA; EMATER/RS. Indicações técnicas para a cultura do milho no RS. Porto Alegre:
FEPAGRO; EMBRAPA; EMATER/RS; FECOAGRO/RS, 2001. p.6-16. (n.7).

EMBRAPA. Centro Nacional de Pesquisa de Solos. Sistema brasileiro de classificação de solos. Brasília : EMBRAPA, 1999. $412 \mathrm{p}$

GASSEN, D.N. Manejo de pragas associadas à cultura do milho. Passo Fundo : Aldeia Norte, 1996. 134p.

INDICAÇÕES TÉCNICAS PARA A CULTURA DO MILHO NO RS. Porto Alegre: FEPAGRO; EMBRAPA; EMATER/RS; FECOAGRO/RS, 2001. 196p. (Publicação Técnica, Boletim n.7)

INSTITUTO DE PLANEJAMENTO E ECONOMIA AGRÍCOLA DE SANTA CATARINA. ICEPA. Florianópolis: ICEPA, 2000. CD-ROM.

INSTITUTO BRASILEIRO DE GEOGRAFIA E ESTATÍSTICA IBGE. Levantamento sistemático da produção agrícola: pesquisa mensal de previsões e acompanhamento das safras agrícolas no ano civil. Rio de Janeiro: IBGE, 2001. p.56-58.

MATZENAUER, R. et al. Análise agroclimática das disponibilidades hídricas para a cultura do milho na região do Planalto Médio do Rio Grande do Sul. Revista Brasileira de Agrometeorologia, Santa Maria, v.8, n.2, p.263-273, 2000.

MINETTO, T.J. Custos de produção: lavouras em plantio direto. Porto Alegre : FECOAGRO/RS, 2000. 81p.

PEGORARO, D.G. et al. Efeito de época de semeadura e adubação na mancha foliar de Phaeosphaeria em milho. Pesquisa Agropecuária Brasileira, Brasília, v.36, n.8, p.1037-1042, 2001.

PROGRAMA MULTIINSTITUCIONAL DE DIFUSÃO DE TECNOLOGIA EM MILHO DO RIO GRANDE DO SUL. Recomendações técnicas para a cultura do milho no estado do Rio Grande do Sul. Porto Alegre : FEPAGRO; EMATER/RS; FECOAGRO/RS, 1999. 146p. (Boletim Técnico, 6)

SANGOI, L. Aptidão dos campos de Lages (SC) para produção de milho em diferentes épocas de semeadura. Pesquisa Agropecuária Brasileira, Brasília, v.28, p.51-63, 1993.

SANGOI, L. et al. Nitrogen fertilization impact on agronomic traits of maize hybrids released at different decades. Pesquisa Agropecuária Brasileira, Brasília, v. 36, p. 757-764, 2001. 